\title{
Assessment of Strategic Messages Communicated for Sustainable Solid Waste Management: A Study of Migori County, Kenya
}

\author{
Marren Akong'o * \\ School of Information, Communication and Media studies, \\ Department of Communication and Journalism, Rongo University \\ PO box 103, 40404, Kenya \\ Prof. Jerry Agalo \\ School of Information, Communication and Media studies, \\ Department of Communication and Journalism, Rongo University \\ PO box 103, 40404, Kenya \\ Dr. James Abila \\ School of Information, Communication and Media studies, \\ Department of Information Science and Informatics, Rongo University \\ PO box 103, 40404, Kenya
}

This research is not funded. (Sponsoring information)

\section{Abstract}

Solid waste management has become great concern for governments and cities due to its effects on health, environment and climate change. The aim of sustainable solid waste management (SSWM) is to achieve circular economy and realize sustainable development goals. Communication plays a significant role in empowering communities with knowledge, influencing behaviour and promoting collaboration on waste management between governments and communities. Past research shows indiscriminate dumping of waste and inadequate knowledge on how to manage solid waste including reduce, reuse and recycle waste among communities in Africa. However, there is limited focus in research on messages communicated for SSWM. This study sought to assess strategic messages communicated for SSWM and media used in the communication. The study conducted in Migori county Kenya, using a mixed methods approach involved a total of 399 town residents sampled using purposive, stratified, and simple random sampling techniques. The study found lack of focus on strategic messages for SSWM in the communication by Migori county government. Communication is uncoordinated, conducted in public meetings, local radio, and by waste management supervisors. Most community members lack knowledge on SSWM practices. The study recommends communication of strategic messages for SSWM to improve community knowledge of SSWM; communication using participatory media accessible to the community; and inclusion of community knowledge in the construction of strategic messages for SSWM.

Keywords:Strategic, Message, Sustainable Solid Waste Management, Community, Participatory Communication.

DOI: $10.7176 / \mathrm{NMMC} / 97-02$

Publication date:August $31^{\text {st }} 2021$

\subsection{Introduction}

Sustainable solid waste management refers to the use of material resources to cut down on the amount of waste generated and where waste is generated it should be dealt with to contribute to economic, social and environmental goals of sustainable development (NEMA, 2014). It is also defined as a management process that involves the integration of economic, environmental and social perspectives (Solani et al., 2015 cited by Tsai, Bui, Tseng, Lim \& Tan, 2020). Sustainable solid waste management (SSWM) helps in mitigating the effects of solid waste on health and environment and supports the realization of circular economy and sustainable development goals (SDGs) number eleven on sustainable cities and communities, and SDG number twelve on sustainable consumption and production.

The United Nations Environmental Programme (UNEP) promotes the adoption of waste management hierarchy (3R) as the blue print for mitigating effects of solid waste on the environment. Presented in an inverted pyramid, the hierarchy emphasizes reduction of waste generated at the source as the most preferred followed by reuse and recycle of waste so as to minimize waste in bins and eventual landfills (UNEP, 2013). Waste reduction and re-use, composting and recycling of products reduce cost of production, promotes circular economy, and reduces effects of waste on the environment thereby contributing to achievement of Sustainable Development Goals (SDGs) number eleven on sustainable cities and communities and twelve on responsible consumption and production. 


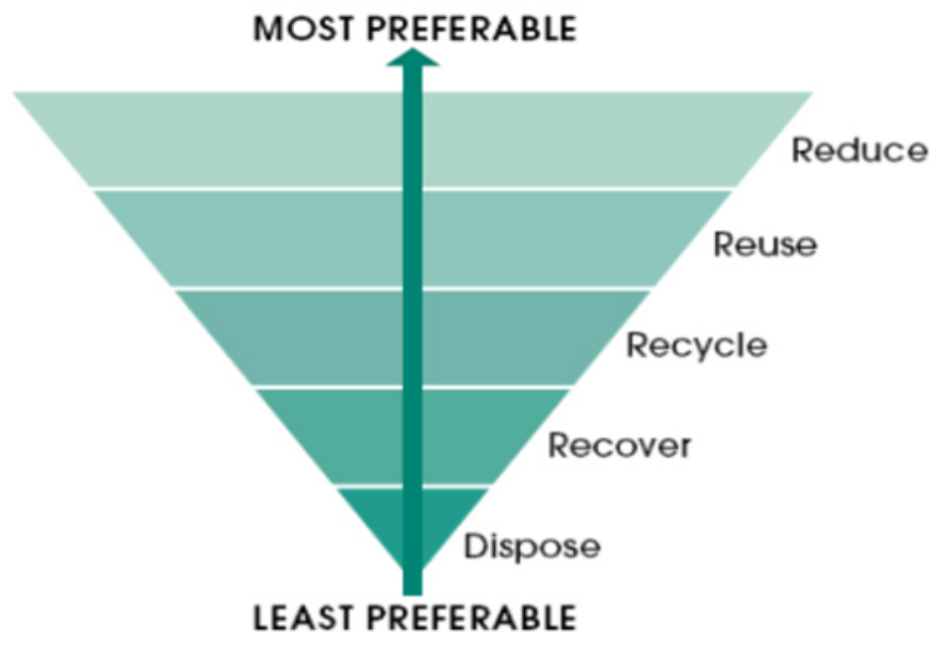

Figure 1: Waste management hierarchy. Source: UNEP (2013).

\subsection{Communication of SSWM (3R)}

Communication improves knowledge and understanding of environmental management practices. Pezzullo and Cox (2018) add that communication evokes feelings; shape and negotiate meaning, values, and beliefs towards the environment. Communication therefore impacts what the environment means to people, how they feel about nature which translate into peoples' relationship with the environment.

Solid waste affects every individual in the community therefore it requires collaboration and participation of all stakeholders; citizens and governments, locally, and nationally. Communication is also a tool for participation. It facilitates collective problem identification, collaborative decision making, and ownership of waste management plans among stakeholders leading to sustainability. Cox and Pezullo (2018) posit that people affected by environmental decision have the right to be involved in the process of making such decisions. In Kenya, the National Sustainable Waste Management Policy (2019) spells out that raising awareness on waste management is crucial for community participation and increased public responsibility for waste management. The policy states that the national and the county governments should provide timely information on waste management to the public using diverse platforms and educate citizens on reduce, reuse, recycle and segregate waste. They should also promote collaboration between the county government and communities so as to increase citizen's ability to participate in waste management. Increased responsibility and participation includes peoples' ability to individually and collectively engage in SSWM. However effective participation in SSWM requires that communities have knowledge on SSWM.

\subsection{Strategic Messages for SSWM}

A message is a symbolic content of communication and a key element of the communication process. It refers to an idea or thought expressed using symbols such as words, phrases, pictures and signs. Symbolic meanings are culturally constructed, determined and then transferred from one generation to the next resulting to the maintenance of cultural meanings thus meanings assigned to symbols used in communication are culture specific. Strategic communication refers to the practice of purposeful communication enacted by a given communicative agent in the public sphere to achieve set goals (Holtzhausen \& Zerfass, 2013). It involves careful selection of messages communicated to specific audiences using carefully selected media to achieve specific communicative objective. Strategic messages use symbols that clearly communicate the intended meanings to the intended audience. Strategic communication of SSWM involves careful selection of messages for SSWM so as to create an understanding of the effects on waste on the environment, SSWM practices, and influence behaviour towards solid waste management.

Pezullo and Cox (2018) posit that an environmental campaign message can address the attitude-behaviour gap if the message refers to an important value that the audience perceive as threatened such as their health or a natural resource. In this sense, the message strategically targets peoples' values. Values are products of culture; they guide social norms, therefore in order to impact community behaviour towards waste management, messages communicated for SSWM should use symbols relevant to the culture and values of the target community; the meanings of those symbols must be familiar to the community.

According to the World Commission on Environment and Development (WCED), local communities are the repositories of wide accumulation of traditional knowledge and experiences that connect humanity with ancient origins (WECD, 1987). The commission suggests thus environmental communication should incorporate 
indigenous knowledge so as to make an impact among the people. Similarly, the Convention for Biodiversity (CBD) acknowledges that the practice of indigenous knowledge transcends all human activities including solid waste management (Kosoe, Diawuo \& Osumanu, 2019). Indigenous knowledge is an accumulation of cultural values of a community thus when used in communication of SSWM such messages impact on peoples' feelings which then influences their behaviour. One of the mechanisms of incorporating indigenous knowledge in communication is by involving them in communication and production of media content for SSWM. In Kenya, the National Environment Policy (2013) provide for participation of local communities so as to incorporate their knowledge and practices in the communication of environmental matters.

Previous studies show lack of knowledge of 3R among waste generators and lack of awareness on good practices for waste management including how people can reduce waste in their households (Sibanda, Obange \& Awuor, 2017; McAllister, 2015; Guerrero, Maas, \& Hogland, 2013; Okot-Okumu, 2012). Guerrero, Maas and Hogland (2013) found that lack of awareness on how people can reduce waste in their households and good practices for waste management among other factors, impact solid waste management in Africa. Another study in Bulawayo (Zimbabwe) found that majority of the populace had no understanding of 3 Rs with majority saying they had never heard of $3 \mathrm{R}$, a factor that resulted to poor waste management among them (Sinthumule \& Mkumbuzi, 2019). In Kenya although $50 \%-80 \%$ of MSW produced is recyclable, this is minimally done. Several industries dealing in recovery of solid waste such as plastics, metals, bottles and textiles for recycling exists but they have not achieved their optimum levels due to inadequate public awareness (NEMA, 2014).

One of the strategies towards recycling is segregation of waste at source. Strategic messages used in communication of waste segregation is the use of colour codes as symbols for recyclable waste, biodegradable and hazardous waste. The use of green, blue and yellow colours for biodegradable, non-biodegradable and paper and glass waste respectively are aimed at creating awareness on how to separate waste according to type so as to make recycling easy. The National Sustainable Waste Management policy (2019) state that both national and county governments should create public awareness on waste colour codes and importance of proper waste sorting, educate waste generators on prescribed sorting methods and carry out public awareness on importance of proper sorting. Despite this policy provision, waste segregation at the source is minimally done in most urban areas in Kenya (NEMA, 2014). In Kisumu City for example, though separate bins for different types of waste were provided, a study found that waste was mixed in all the bins and during collection to the dumpsite (Sibanda et al., 2017). Aura (2013) concludes that the culture of waste separation is not engrained in the public in Nairobi.

Lack of separation of waste even when colour coded waste bins are provided can be attributed to lack of education and understanding of the meanings of the colours, lack of noticeability of the colours and location of the bins. A study on the effects of colour preference and noticeability on waste sorting behaviours found that individuals failed to notice bins with colours they least prefer and that unit colour and noticeability affect waste collection and separation performance (Leeabai, Khaobang, Viriyapnitchakij \& Areeprasert (2021). Though green, yellow and blue colours are the conventional symbols different types of waste, waste generators may fail to separate waste due to lack of understanding of the meanings of the colours and or assigning a different meaning to the colours provided. This is because meanings are culturally assigned. Thus presence of colour coded bins without effective communication may yield limited results in waste separation.

In Sri Lanka, a study found that though the Municipal Council gave bags to household for waste separation, some householders did not use the bags since they felt they were not suitable; some ended buying their own baskets for waste and thus stopped to separate waste (Pinawala, 2016). The study found that $68 \%$ of people in Sri Lanka were not adequately informed about the implications of combining waste and benefits of waste separation at source.

\subsection{Media used in communication of SSWM}

The media plays an important role in creating awareness and influencing peoples' attitudes towards environmental behaviour change. The mass media such as radio, print media and TV sets the agenda and diffuse information to a wide audience, thereby improving environmental knowledge. However, studies have shown that high level of awareness on waste management created using the mass media do not correspond to peoples' participation in waste management as individuals did not exhibit positive behavior towards waste management (Nunez \& Moreno, 2016; Patrick, 2015; Obuah \& Okon, 2017). Flor (2004) posits that environmental consciousness is a "function of society's collective cosmology, worldviews and values" which can seldom be changed using T.V adverts, news release and posters- conventional promotional time-bound communication programmes. Critics argue that political economic interests of the media, limited coverage of environmental issues, limited training among journalists and passive depiction of environmental issues in the mass media contribute to the media's inability to influence pro-environmental behaviour (Koser, 2017; Nunez \& Moreno, 2016; Pezullo \& Cox, 2018; Ruiz, Martin \& Cabrera, 2011;).

Other than the mass media, traditional media such as folk media, storytelling, puppetry and songs have been used in environmental communication management. Flor (2004) observes that communication is a function of 
culture and since culture and environment and inextricably linked, environmental education and communication must take into account cultural dimensions of the people. Traditional media are rooted in peoples' values and culture which provides rich knowledge about the natural environment. Indigenous knowledge such as taboos, communal labour significantly impact on solid waste management but their implementation is threatened by modern religion and lifestyles especially in urban areas, and adoption of modern technology by policy makers. Other aspects of traditional media include the use of popular music and video recordings which are particularly popular with the youth.

Nonetheless, improvement of technology has changed all aspects of communication including environmental communication. Pezzullo and Cox (2018) observe that digital media is useful in promoting dialogue on environmental issues in three ways; alerting, amplifying and engaging. Digital media has capabilities of user generated content that makes it effective in creation and sharing of messages. Using digital media, individuals alert communities on environmental problems and risks such as floods leading to informed decision making. Social media posts on environmental issues such as pollution elicit public debate and environmental activism that may prompt action from authorities. Digital technology also amplifies environmental communication through social media circulation of events and images prompting public debate on matters that would probably receive limited attention from the mainstream media. Circulation of photographs and images on environmental issues shape community perception of environmental issues that can lead to social change. One major advantage of digital media is its affordances in creating virtual communities and in enhancing participatory communication among communities in transcendence. Social media therefore makes it possible for communities to collaborate in the communication of SSWM irrespective of geospatial differences.

The impact of digital media, especially social media, in communication abounds in literature. However, the use of social media in promoting participation in communication for sustainable solid waste management is limited in literature. Since social media combines both elements of traditional and new media, it can promote awareness and enhance participatory communication among communities leading to sustainability.

Collaborative communication between waste management experts and communities leads to empowerment, promote collective decision making and transform social behaviour towards waste management. This is because people are more likely to engage in recycling when they see others around them do the same. Individuals can also transform their behaviour towards waste management for fear of being seen as outsiders. (Guerrero et al. 2013; McAllister, 2015). Pezullo and Cox (2018) add that whereas beliefs do not have a direct influence on behavior, values and cultural norms have a direct role on behaviour.

Despite limited awareness on waste management practices such as recycling and waste separation among communities, limited research has been done on messages communicated for waste management. Most studies have focused on solid waste management practices, challenges and solutions (Aurah, 2015; Guerrero, et al, 2013; Kagumba, 2017; McAllister, 2015; Ndwiga et al, 2019; Tsai, Bui, Tseng, Lim \& Tan, 2020) and on the use of mass media such as Radio and TV in creating awareness on waste management (Ferdinand \& Patrick, 2015; Kosoe, 2017; Obuah \& Okun, 2013; Otinga \& Ngigi, 2014). This study intended to bridge this gap by assessing strategic messages communicated for SSWM so as to understand how this impacts SSWM practices among the communities.

The study was guided by the following objectives.

i. To assess strategic messages communicated for sustainable solid waste management in Migori County.

ii. To explore media used in the communication of SSWM.

iii. To establish community awareness of SSWM practices.

The following questions were asked in the study

i. What key messages for SSWM does Migori County government communicate to the communities?

ii. Which media does Migori county government use to communication SSWM?

iii. To what extent are communities in Migori County aware of SSWM practices?

\subsection{Theoretical framework}

This study was guided by Participatory Communication theory by Paulo Freire (Freire, 1970). Freire proposes that dialogic communication leads to critical consciousness and empowerment of individuals leading to social transformation. Participatory communication is opposed to one - way communication where information is deposited in the minds of audience with limited participation form them. Individuals must be able to speak their voice their own way, a process that leads to critical consciousness and personal transformation Freire points out that dialogue cannot be reduced to the act of one person "depositing" ideas in another nor can it become a simple exchange of ideas to be consumed by the discussants" rather, individuals themselves must give their views their own way (Freire, 1983; 1993).

In Development Communication, participation communication is a process of collaboration between development experts and communities aimed at collective identification of development problems, solutions and decision making leading to ownership of development programmes. It is a people driven initiatives in finding 
local solutions to local problems leading to sustainability. Participatory communication theory is premised on the argument that solutions to local problems are local based therefore participation of the community in dialogic communication facilitate inclusion of local ideas in finding those solutions.

In this study Participatory Communication provides a paradigm for active participation of the community in the communication of SSWM by involving them in the construction and sharing of messages for SSWM. It is also anchored on the realization that inclusion of indigenous knowledge in strategic communication of SSWM promotes a better understanding of SSWM practices, empowerment leading to sustainability. The study argued that in order to impact the people, messages communicated for SSWM should relate to cultural realities of the communities. Such messages should be constructed and communicated by the people themselves using symbols relevant to their culture.

\subsection{Method}

This study was conceptualized from a pragmatic philosophical paradigm. Using mixed methods approach. Information on strategic messages for SSWM communicated by Migori County government was obtained using interviews with the department of environment where waste management is domiciled, the municipalities and representatives from the community. The messages were assessed based on provisions of The National Sustainable Waste Management policy (2019) which stipulates that both national and the county governments should carry out public awareness on waste segregation, reduction, re-use and recycling. Focus group discussions were held with community members to explore further on communication of SSWM and ascertain their awareness on SSWM practices. A total of 399 adults from three towns in Migori County participated in this study. Out of these, 23 participated in interviews while the rest responded using focus group discussions and semi structured questionnaires. The study used stratified, purposive and simple random sampling techniques. Data obtained from focus group discussions were further explored using questionnaires to determine the generalizability of the qualitative findings. Qualitative data was and analyzed thematically while quantitative data was analyzed using SSPSS version 26. The two sets of data were merged in discussions. Data were presented using descriptive statistics, charts, tables, and quotes from respondents.

\subsection{Study Area}

This study was conducted in Migori County, one of the devolved units in Kenya. In Kenya waste management is devolved to the 47counties. The Kenyan government plans to achieve sustainable development goals, vision 2030 and agenda 2063 on sustainable communities and cities. The County governments Act (2012) stipulates that county governments should manage waste, provide information about waste management and collaborate with the community on waste management. The National Sustainable Waste Management policy stipulates that both national and the county governments should carry out public awareness on waste segregation, reduction, re-use and recycling. Despite these provisions, solid waste management in Kenya remains a challenge. Poor waste management practices characterized by littering and illegal dumping of waste in roadsides and rivers is prevalent in many urban areas in Kenya including urban areas in Migori County. Poor waste management, especially in urban areas has contributed to poor sanitation and spread of disease such as diarrhea, malaria and respiratory infections and impacts on its development plans (Migori County Integrated Development Plan, 2018-2022).

\subsection{Findings}

\subsection{Strategic messages communicated for sustainable solid waste management}

The study found that key message communicated by Migori county government to the community was proper waste disposal using dustbins and designated dumpsites. Posters with writings "don't dump waste here" were also used to warn people against illegal dumping. These messages were directed from the department of environment and natural resources in the county and the municipalities to the community.

K.I.3: $\quad$ The key message that we have passed, make sure you have a dustbin in front of your shop. Don't put waste in drainages, they block the drainages.

K.I.4: $\quad$ Posters are not purely about solid waste but among other things solid waste will be among the messages.

K.I.3: $\quad$ The cleaners of the town directly communicate to waste generators. After sweeping they tell them: usimwage takataka hapa (don't dump waste here).

However, most community members mentioned that Migori county government does not communicate about waste management. From the survey findings, majority of community members, $115(49 \%)$ felt that the county government does not communicate about SSWM while 95(41\%) of respondents agreed that the county government communicate about use of dustbins. 


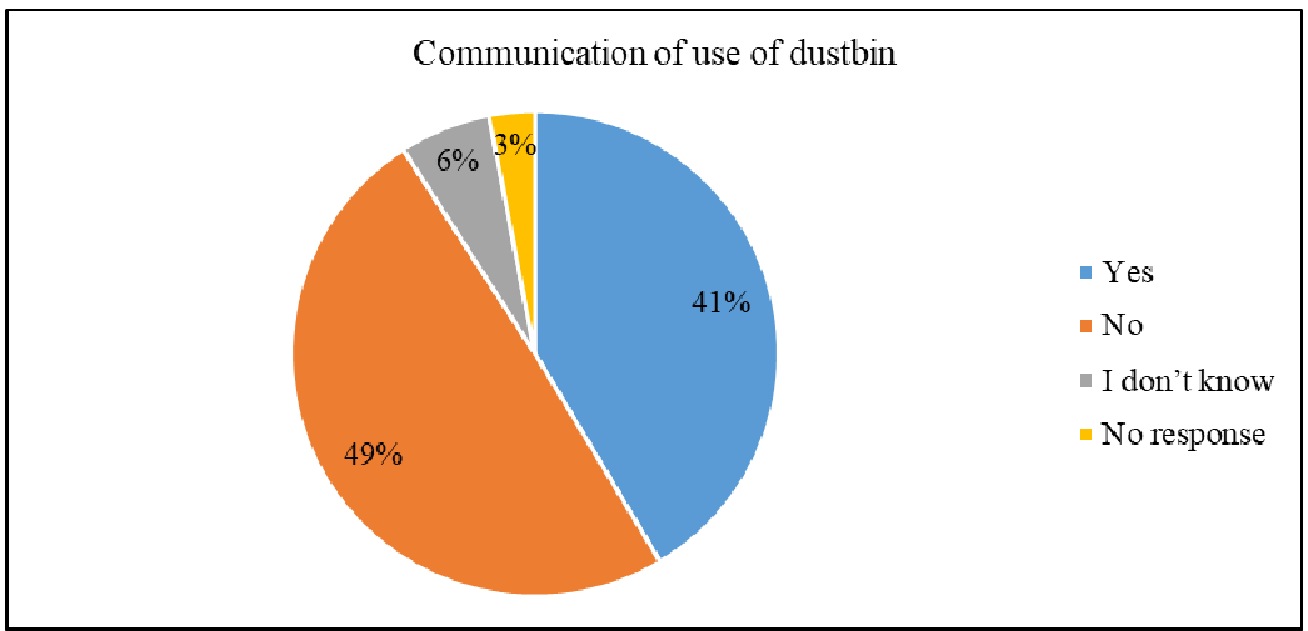

Figure 2: communication of use of dustbin

These findings are similar to previous studies which showed that limited communication of waste management contributes to lack of awareness on how to manage solid waste among the public (Guerrero, Maas, \& Hogland, 2013; Okot-Okumu, 2012;Sibanda, Obange \& Awuor, 2017). Though some community members agreed that the use of dustbins is communicated to them, the study found that it did not translate into practice. Study found that most traders do not use dustbins and those who use them still dumped solid waste by the roadsides and drainages in the towns. At the same time those who used dustbins feel that waste collected in the skips are not regularly collected by the county government leading to sprawling of waste therefore it did not make a difference whether they use dustbins for waste disposal or not.

\subsection{Strategic messages for Reduce, Reuse and Recycling, (3R)}

The study found that Migori county government does not have strategies for messaging $3 \mathrm{R}$. There is limited focus on 3R (reuse, reduce and recycling). The department of environment considers 3R a high order waste management technique that requires a lot of resources therefore they do not focus on it but on proper waste disposal. This view is shared with the community members, most of whom mentioned that $3 \mathrm{R}$ is a new phenomenon that they have not heard about.

We have not heard communication about SSWM in this town. If they are done in meetings, we don't attend those meetings we don't even know where and when they are held (Group 5, Migori town)

Hamna mawasiliano kuhusu taka.hilo halipo (residents, Isebania town).

(There is no communication about waste... that does not exist). (Group1, Isebania town).

\subsubsection{Messages on Reduce waste}

Most respondents, $158(68 \%)$ mentioned that waste reduction is not communicated by Migori county government, 39(17\%) agreed that there is some communication about waste reduction while $35(15 \%)$ said that they do not know whether it is communicated.

Burning of waste is one of the techniques used by the communities to reduce waste in the towns. Communication does not focus on burning of waste and messages communicated to discourage burning of solid waste are lacking. Some respondents mentioned that they are encouraged to burn waste while others mentioned that though the county government does not talk about how to burn waste, they resort to burning so as to reduce the amount of waste that often accumulates in the skips and temporary dumpsites.

\subsubsection{Messages on Reuse waste}

In Rongo town the municipal council had communicated about 3R during one public citizen forum in the year 2020. In Migori and Isebania towns, there are no messages directed towards waste reuse. When community members were asked whether the county government communicate about reuse waste, only $30(13 \%)$ answered yes, $164(71 \%)$ said no while $38(16 \%)$ did not know whether re-use waste is communicated.

\subsubsection{Messages on waste recycling}

Though the departments in charge of waste management mentioned that they communicate about both recycling and reuse waste, most community members mentioned that recycling is not communicated by Migori County government. $171(74 \%)$ said no, $26(11 \%)$ said yes while $35(15 \%)$ do not know whether recycling is communicated. The minimal communication for waste recycling was found in all the three towns. In Rongo town 20(67\%) answered no while $10(33 \%)$ do not know. In Migori town majority, 106(70\%) answered no, $25(16 \%)$ answered yes, while $21(14 \%)$ do not know whether waste recycling is communicated by the county government of Migori. In Isebania town 45(90\%) answered no, 1(2\%) yes while 4(8\%) do not know.

There is no communication from the county government on how to manage waste. People have not heard or 
seen forum where they can talk about solid waste management (Group 2, Rongo town).

\section{Does Migori county government communicate mesages about these SSWM practices?}

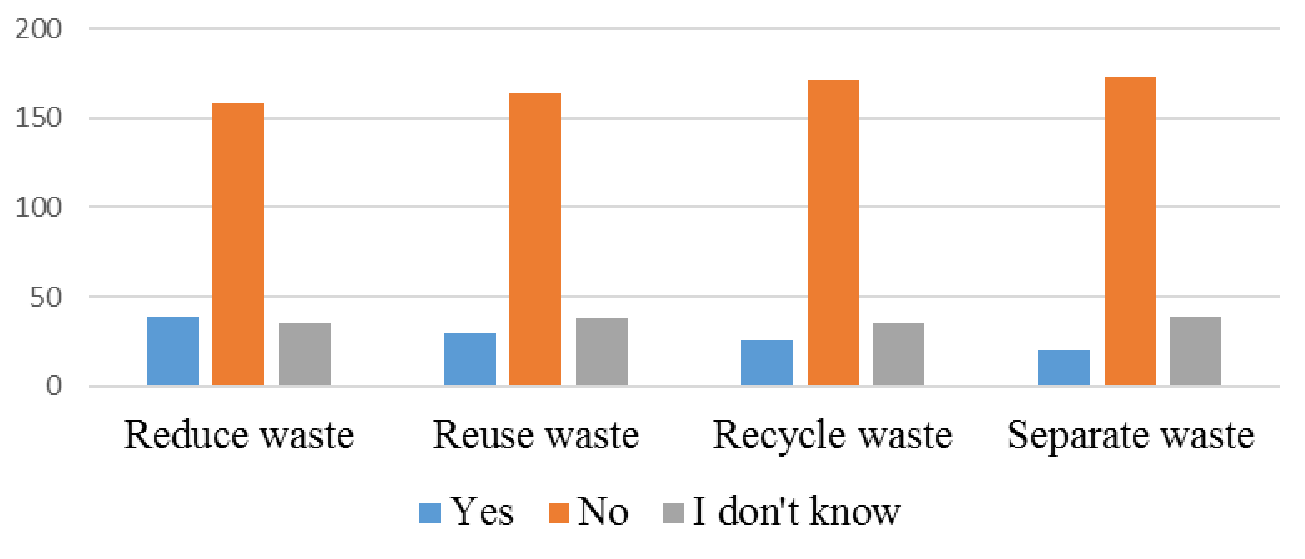

Figure 3: Messaging SSWM

From figure 3, most study respondents mentioned that $3 \mathrm{R}$ is not communicated by Migori county government which shows that there is limited focus on communication of $3 \mathrm{R}$. The main message communicated for SWM by Migori county government is the use of dustbins. Dustbins are meant for waste collection before final transfer to dumpsites. Emphasis on use of dustbins alone does not translate to SSWM since people are likely to put all sorts of waste in the same dustbin in disregard for separation, reuse and recycling. In this study community members mentioned that waste is waste and they do not separate. Study respondents also mentioned that there is no need to separate waste at source since even when they separate waste at the source, all waste eventually gets mixed during transportation and in the dumpsites. Lack of waste separation not only makes waste management inefficient but also contributes to air pollution during the process of decomposition. In this case lack of waste separation facilities affect communication of waste separation.

\subsection{Community knowledge of SSWM (3R) practices}

This study found limited knowledge of SSWM (3R) practices among members of the community in Migori County. Communication of solid waste management by the county government is rarely done and most community members are were not aware when such communication takes place. This contributes to their lack of knowledge of SSWM (3R) practices.

K.I.15: People do not know. They have not been educated on how to handle waste. There is very shallow knowledge on how to manage solid waste. The government has not reached the people to educate them. There is no proper channel to communicate to the proper on how to control and mange solid waste.

There is no communication from the county government on how to manage waste. People have not heard or seen forum where they can talk about solid waste management (Group 2, Rongo town)

There is no communication about waste... that does not exist. (Group 1, Isebania town).

Table 2.1 Community knowledge of SSWM practices.

Do you have knowledge on the following sustainable waste management practices?

\begin{tabular}{|l|l|l|l|}
\hline \multirow{2}{*}{ SSWM Practice } & \multicolumn{3}{|l|}{ Responses $(\mathrm{n}=232)$} \\
\cline { 2 - 4 } & Yes & No & Non-comital \\
\hline Re-use waste & $30(13 \%)$ & $164(71 \%)$ & $38(16 \%)$ \\
\hline Reduce waste & $39(17 \%)$ & $158(68 \%)$ & $35(15 \%)$ \\
\hline Recycle waste & $26(11 \%)$ & $171(74 \%)$ & $35(15 \%)$ \\
\hline Separate waste & $20(9 \%)$ & $173(75 \%)$ & $39(16 \%)$ \\
\hline
\end{tabular}

From table (1.1) above, majority of the community lack knowledge of 3R. Limited knowledge is higher on separation (75\%). This study found high number of those who lack knowledge on 3R compared to Bulawayo (Zimbabwe) where $68 \%$ of the populace in Bulawayo (Zimbabwe) had no understanding of 3 Rs, majority mentioning that they had never heard of 3R (Sinthumule and Mkumbuzi, 2019). Similarly, Guerrero, et al., (2013) found lack of awareness on how people can reduce waste in African countries. 


\subsection{Media used in the communication of SWM}

The study found that awareness on waste management is created through local radio, posters, waste management supervisors, Chiefs' Baraza, Public citizen forums and meetings with representatives of the community. Communication however is uncoordinated, irregular and mostly takes place when there is public outcry about poor waste management in the towns. It was also found that during public forums some community members raise complains prompting discussions between government officials and the public however most community members do not the public forums.

K.I.2: $\quad$ We use media, radio stations, issue leaflets or letters to waste generators and communication is also done orally. We have supervisors on the ground; ...... All these work together to disseminate information to our people.

K.I. 3: The cleaners of the town directly communicate to waste generators. After sweeping they tell them: usimwage takataka hapa (don't dump waste here).

K.I.4: $\quad$ Posters are not purely about solid waste but among other things solid waste will be among the messages.

The study found that public fora, chiefs' Baraza and stakeholder meetings are not purely organized for discussion on waste management but for other purposes such as budgeting, town planning and security. During such meetings, members of the community sometimes raise concerns on the problem of poor waste management in the county prompting discussions about how to manage solid waste in the towns. Most community members mentioned that they have not heard of any communication about waste management by their county government while others do not know which media or forum where solid waste management is communicated.

During the survey, majority; $86(37 \%)$ felt that there is no communication; 54(23\%) mentioned that radio is used; 15(6\%) cited public citizen fora; $10(4 \%)$ cited chiefs' Baraza; 9(4\%) cited waste management supervisors; $6(3 \%)$ cited meetings with stakeholder representatives; $2(0.9 \%)$ cited leaflets and posters while $50(22 \%)$ do not know the media used.

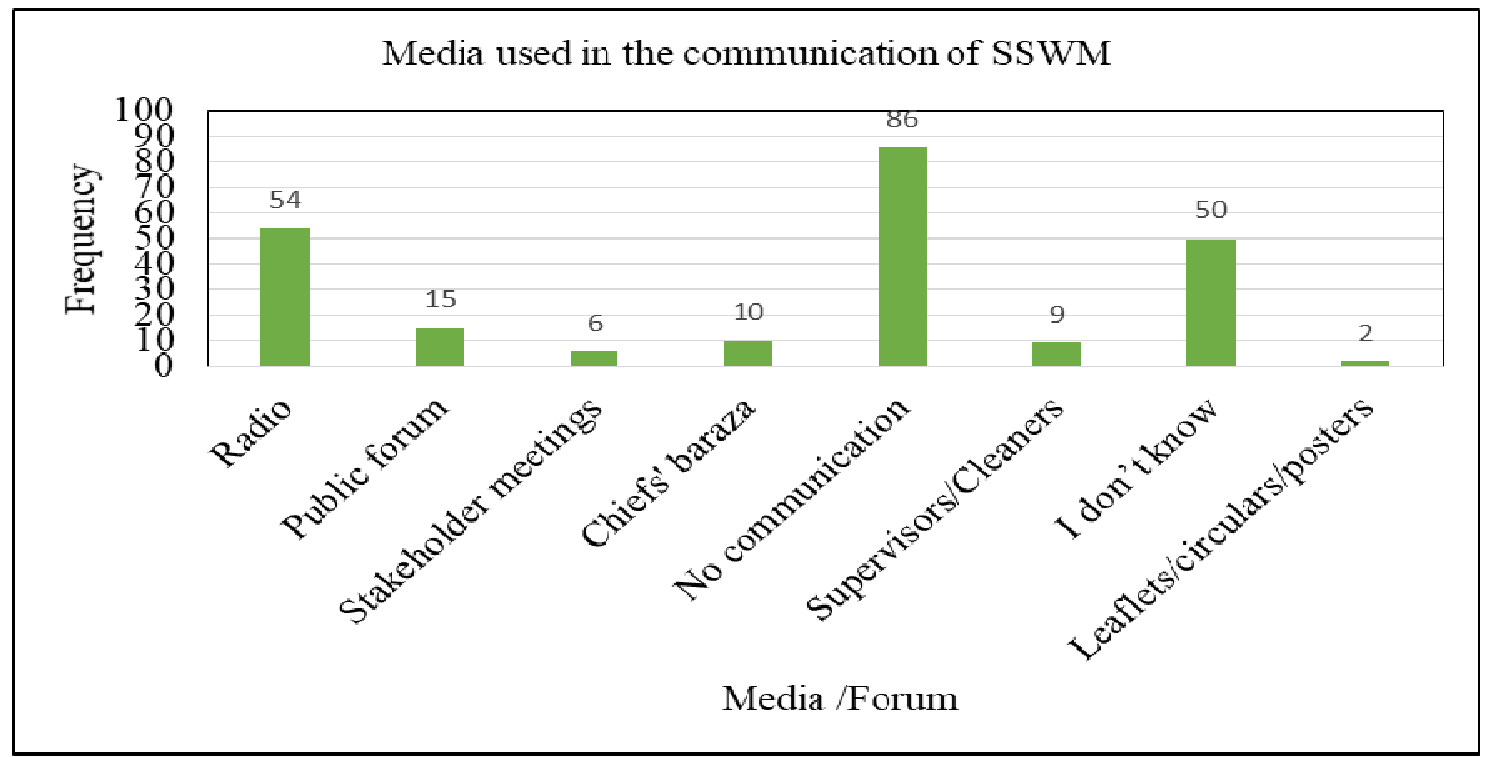

Figure 4: Media used in the communication of SSWM.

From figure 4, majority of study respondents mentioned that the county government does not communicate about SSWM. Though radio has a wide coverage in Migori County, only $23 \%$ mentioned that SSWM in communicated in radio. This finding confirms earlier studies (Oting'a \& Ngigi, 2019) which showed limited coverage of environmental issues by the mass media in Kenya.

Waste management supervisors are employed by the county government to oversee management of waste in the towns. The study established that waste supervisors are expected to create awareness on waste management during their regular duties of monitoring collection of waste in the towns. However, only $4 \%$ of the study respondents mentioned that this takes place. Chiefs' Baraza are community meetings organized by the local chiefs to discuss about local administrative issues with the local community. Most community members do not attend chiefs' Baraza. Besides, Baraza focuses on administrative issues and not waste management.

Chief does not get involved in SSWM that is the work of county not chief. Waste management is handled by

the environment not chiefs. (Group, 9 Migori town).

Public citizen forums were organized by the county government annually to involve the public in budgeting process as required by the constitution. The forums had also been organized by municipalities when issues such as security and town planning arose in the towns. The study found that most community members do not attend 
public citizen forum due to lack of information and invitation to attend public citizen forum. Others also mentioned that public forum are organized for political reasons and only those politically affiliated to the organizers are invited. Some community members feel that public citizen forum are merely used to show public participation but nothing positive results from the meetings. The study found since the meetings have many other key agenda limited attention is accorded to SSWM.

I have attended two of such meetings but there is nothing like education about SSWM. Leaders from different sectors will present different issues. Nobody takes their time to educate people about SWM. We complain that waste is not collected in town, they say it will improve, the other time they said that every shopkeeper should have their own dustbins. That is all then they go to another agenda (representative of the community, Migori town).

The study found that municipalities hold consultative meetings with representatives from different sectors in the towns during which the department of environment and the municipalities create awareness on waste management. Community representatives who attend the meetings are then expected to relay information from the meetings to other members of the community they represent. However the study found that most community members do not know who represents. Besides, not all representatives who attend the meetings share information with the rest of the community.

You may find that meetings are held but those invited are not representatives of traders; they have no connection at all and sometimes you (representatives) are not informed that there was a meeting. I'm not sure how invitations to those meetings are done (representative from the community).

May be they go but they don't share with us. They have never come from those meetings and shared with us or called a meeting (Group 3, Migori town).

These findings confirms observations by Pezzullo and Cox (2018) that public hearings may be ineffective in facilitating community participation in environmental decision making since the meetings may be unrepresentative of the wider community.

\subsection{Discussions}

Findings from this study showed that Migori county government give limited focus on strategic messages for SSWM in the communication for waste management. The National Sustainable Waste Management policy indicates that county governments should carry out public awareness on waste segregation, reduction, re-use and recycling; however, this study found lack of communication of colour codes and waste sorting.

Lack of focus on strategic messages in the communication of 3R results to limited knowledge of SSWM practices among the community most of whom do not practice sustainable solid waste management. The study found that community members in Migori County burned waste as a way of reducing waste in the dumpsites. Waste separation at source was not practiced and a mix of all types of waste was exhibited in the dumpsites. Burning of waste is highly discouraged by the Stockholm Convention because it leads to emission of greenhouse gases such as methane and contributes to global warming. Emissions from burned waste also leads to respiratory infections and health risks. In order to discourage burning of waste, communication should focus on messages on stopping burning of solid waste.

Even though Migori County government disseminate information of waste collection using dustbins, littering and illegal dumping of waste is still prevalent in urban areas of Migori County. Most waste generators in the community do not use dustbins and those who use them in the households still dump waste on the roadsides and drainages in the towns thereby compromising the very objective of SSWM.

These findings are similar to those found in Sri Lanka where though the Municipal Council gave bags to household for waste separation, some householders did not use the bags feeling that the bags were not suitable. The study in Sri Lanka found that $68 \%$ of people were not adequately informed about the implications of combining waste and benefits of waste separation at source (Pinawala, 2016). Similarly, this study found that $75 \%$ of the community in Migori County lack knowledge on waste separation. SSWM begins with waste minimization by waste generators; however, provision of litter bins without emphasis on waste minimization compound the problem of increased waste in the landfills and high costs of waste management.

This study found that the county government lacks strategic messages for waste separation. Conventional Colour codes symbolizing different types of waste is also not communicated. This contributes leading to lack of awareness on waste separation. However in order to effectively separate waste, users of the bins must have accurate interpretation of messages communicated for waste separation. The conventional use of green, blue and yellow colours may not be culturally appropriate for all communities because different communities have different meanings associated to colours. Research has shown that colour preference and noticeability affect waste collection and separation performance ((Leeabai, et al., 2021). Strategic messages for waste separation should incorporate community views in the choice of symbols (such as colour) used in the communication of waste separation. The symbols should relate the cultural realities of the community. Pezzullo and Cox observe that in order to impact behaviour, communication about the environment should relate to things that people value. 
Peeple and Depoe (2014) emphasize that people must have a voice on matters about their environment. They caution against lack of community voice saying that as voice goes, so does that environment. Inclusion of community views in communication can be achieved by collaborating with the community in generation of strategic messages for waste management in a participatory approach. Tsai et al., (2020) posit that stakeholder participation is one of the attributes for achieving sustainability in waste management.

Community participation in communication also empowers them with knowledge so that they develop confidence that they are able to carry out the task. There are three advantages of participation in communication on SSWM: It leads to critical consciousness so that individuals begin to understand the effects of poor waste management and their roles on how to change those situations; it leads to empowerment with knowledge; and promotes collective decision and implementation of solutions to waste management problems leading to sustainability.

In his Pedagogy of the Oppressed, Freire argues that the oppressed must be allowed to speak their own voice their own way leading to their emancipation (Freire, 1983). Communities in Migori face health challenges created by poor waste management yet they practice littering and indiscriminate dumping of waste. The people have not realized that they are capable of transforming these unhealthy environmental practices. By collaborating with the county government in communication, the communities can actively generate strategic messages for SSWM and make decisions on how to practice SSWM. Locally generated messages by the people themselves are more likely to relate to their cultural realities and impact their behaviour than messages deposited in them by external experts. Using participatory communication, the community does not become recipient of information from outside but active participants in the communication process by generating content for SWMM. Flor (2004) opines that communication strategies for environmental management should ensure that people are not passive receivers of information but actively generate information as well. According to Servaes (2008) participation of the community in communication leads to sustainability since the community participate in decision making which leads to ownership of the programmes.

Strategic communication requires strategic choice of media. Such media should be accessible to the target audience and have capabilities of relaying the intended message in the intended way. This study found that, awareness on waste management using public meetings, Chiefs Baraza and stakeholder meetings did not reach majority of the community.

Studies show that creation of awareness on SSWM using the mass media has limited impact on waste management behaviour (Patrick \& Fedinard, 2014). This is because while people may be aware of recycling, people tend to engage in SSWM behaviour when other people around them do the same. Pezzullo and Cox (2018) observe that and cultural norms have a direct role on environmental behaviour. This study found that radio was used (though limited) by Migori County government to create awareness on SSWM. However most community members did not receive information from the radio. Knowledge on how to reduce, reuse and recycle waste can be improved using Participatory community radio.

Participatory community radio provides a public sphere where the community actively participate in discussion of SSWM leading to empowerment and collective decision making towards sustainable solid waste management. In Boukina Faso, community radio magazine programme enabled the local community to control soil degradation, deforestation and waster waste (Shahzala \& Hassan, 2019). Therefore instead of using forum such as public forum and chiefs Baraza which is poorly attended by the community, community radio offers an alternative media where the community engage in discussions which are later broadcast for the rest of the public. Besides, with the affordances of web 2.0 technologies, communication on community radio can be shared with other member of the community using social media platforms.

Participatory media such as social media also offers opportunity for personalized communication in a strategic way. It enables creation of user generated content which can then be shared with other community members to create awareness on SSWM. Videos and demonstrations of how to separate and reuse waste when shared through social media platforms such as You-tube and WhatsApp can increase knowledge on SSWM among the community. Similarly those who engage in waste recycling can share information with other networks of waste collectors and create a community of recyclers.

\subsection{Conclusion}

This study concludes that lack of focus on strategic messages for SSWM in the communication of SSWM by Migori County government contributes to lack of knowledge on SSWM practices among the communities in Migori County. Though use of colour codes in communication of waste separation is stipulated in the National Environmental policy (2013), Migori County government does not communicate colour codes and waste separation in the communication for SSWM due to lack of resources for waste separation. The study concludes that limited and uncoordinated communication of waste management using media inaccessible to most members of the community hampers the community from participating in the communication of SSWM. Lack of focus on strategic messages and lack of participation in communication contributes to lack of responsibility for waste 
among the community in the urban areas.

This study recommends focus on strategic messages in the communication for SSWM programmes so as to increase community knowledge on SSWM. Governments and municipalities should embrace community participation in the communication of SSWM. They should also incorporate local knowledge in the formulation of messages communicated for SSWM. The study recommends use of participatory community radio and social media platforms to promote participatory dialogue in SSWM.

The study concluded that since communication does not focus on strategic messages for SSWM the community members lack knowledge and do not practice SSWM. The study recommends further research on community understanding of meanings in messages communicated for SSWM and how this impact their waste management practices.

\section{References}

Aurah, C. M., (2013). Assessment of Extent to which Plastic Bag Waste management Methods Used in Nairobi City Promote Sustainability. American Journal of Environmental Protection. 1 (4) 96-101. Doi: 10.1269/env-1-4-4

County Government of Migori. (2018). County Integrated Development Plan 2018-2022. Republic of Kenya. Retrieved from https:/rogkenya.org/...Migori-County.

Flor, A. G. (2004). Environmental Communication: Principles, Approaches and strategies of Communication Applied to Environmental Management. University of Philippines Open University.

Freire, P. (1983). Pedagogy of the Oppressed. New York: Continuum.

Guerrero, L., Maas, G., \& Hogland, M. (2013). Solid waste management challenges for Cities in developing Countries. Waste Management, 220- 232.

Holtzhausen, D.R. \& Zerfass, A. (2013). Strategic communication- Pillars and perspective on an alternative

Paradigm. In K. Sriramesh, A. Zerfass and J.-Kim (Eds.), Current Trends and Emerging Topics in Public Relations and Communication Management. (Pp283-302). New York, NY: Routledge.

Khreejit, C.P., Flor, A.G. (2013). Participatory Development Communication for natural resources

Management in Ratchaburi province, Thailand. Procedia-Social and Behavioural sciences, 103, 703-709 doi:10.1016/j.sbspro.2013.10.390

Koser, R. (n.d). Role of Mass Media in Public Awareness about Household Waste Management: A case Study in Lahore (Pakistan). A thesis submitted in partial fulfillment of the Requirements for the degree of Master in International Environmental Studies. Norwegian University of Life Sciences As, Norway.

Kosoe, E. A., Diawo, F., \& Osumanu, I., K. (2019).Looking into the past: Rethinking Traditional Ways of Solid Waste Management in the Jaman South Municipality, Ghana. Ghana Journal of Geography Vol. 11(1) pages 228-244.

Lakshmikantha, N. \& Malur, P.G. (2014). Waste management public awareness and communication: A study on the role of T.V in waste management. Orient Journal of Law and social sciences Vol.VIII, Issue 6, Pg. 8695.

Leeabai, N., Areeprasert, C., Khaobang, C., Viriyapanitchakij, N., Bussa, B., Dilixiati, D., \& Takahashi, F. (2021). The Effects of colour preference and noticeability of trash bins on waste collection performance and waste-sorting behaviours. Waste Management. 121. 153-163. 10.1016/j.wasman.2020.12.010.

Marshall, R.E., \& Farahbakhsh, K. (2013).Systems approaches to Integrated Solid Waste Management in developing countries. Waste management, 33(4) 9881003.

McAllister, J. (2015). "Factors influencing solid-waste management in the Developing World". All Graduate Plan B and other Reports. 528. https://digitalcommons.usu.edu/gradreports/528

Ministry of Environment and Forestry. (2019). National Sustainable Solid Waste Management Policy. Republic of Kenya.

Ndwiga, M., Nyambura, L., Kuloba, M.B. \&Ngaithe, L. (2019). Does Awareness Influence Choice of Waste Disposal Methods? A case of Migori Town, Kenya. Civic and Environmental Research Vol.11 no.7. DOI: 10.7176/CER.

NEMA. (2015). The National Solid Waste Management Strategy. Nairobi: National Environment Management Authority (NEMA).

Ngigi, P.K., \& Kinyua, C. (2014). The Concept and Philosophy of Community Radio Stations in the Kenyan Context. J Mass Communication Journalism 5: 233. doi:10.4172/2165-7912.1000233

Nunez, R., \& Moreno, O.J. (2016). Communication and Environmental Conservation: advances and Challenges in Latin America. Revista Latin de communication Social, 71 pp.015-039.

Obuah, P.F. \& Okun, G.B. (2017). Environmental Communication Strategies of the Rivers State Waste Management Agency (RIWAMA): Implications for sustainable waste management in Nigeria" International Journal of Development \& Sustainability. Vol.6 No. 11 p. 154-558.

Ombis, L.O. (2017). A study report on Awareness on Environmentally sound Solid Waste Management by 
Communities and Municipalities in Kenya. Ministry of Environment and Natural Resources. Republic of Kenya.

Otinga, C.S. \& Ngigi, S. (2018). Media and Environmental Awareness in Kenya: A case of TV. New Media and Mass Communication. Vol. 67. ISSN 2224-3275.

Oyugi, E., Boru W., Obonyo, M., Githuku, J., Onyango, D., Wandeba, A..., Gura, Z. (2017). An Outbreak of Cholera in Western Kenya, 2015: A case Control Study. The Pan African Medical Journal. doi:10.11604/panj.supp.2017.28.1.9477.

Patrick, A. \& Ferdinard, O. (2014). Adopting Broadcast Media Sensitization Campaigns for Solid Waste Management. Journal of Mass communication and Journalism.4: 8. DOI: 10.4172/2165 7912.1000208

Peeples, J. \& Depoe, S. (Eds.). (2014). Voice and Environmental Communication. New York: Palgrave Macmillan.

Pezzullo, C. P., \& Cox, R. (2018). Environmental Communication and the Public Sphere (5 ${ }^{\text {th }}$ ed.). London: Sage. Pinnawala, M. (2016). Community Participation in solid waste management: A case of Kurunagala Municipal

Council in the North Western province of Sri Lanka. Malaysian Journal of Science 35 (2): 63- 72 (2016)

Republic of Kenya (1999). Environmental Management and Co-ordination Act, 1999 No 8 of 1999 EMCA.

Kenya Gazette Supplement No 74(Acts No 5).

Republic of Kenya. (2010). The Constitution of Kenya. National Council for Law Reporting. Nairobi.

Republic of Kenya. (2012). County Governments Act, 2012.

Servaes, J. (Eds). (2008). Communication for Development and Social Change. Thousand Oaks: Sage.

Servaes, J. (Eds). (2013). Sustainable Development and Green Communication: African and Asian Perspectives.UK: Palgrave Macmillan.

Shahzalal \& Hassan, A. (2019). Communicating Sustainability: Using Community Media to Influence Rural People's Intention to Adopt Sustainable Behaviour. Sustainability. MDPI.

Sibanda, L.K., Obange, N. \& Awuor, F.O. (2017). Challenges of Solid Waste Management in Kisumu, Kenya. Springer Science + Business Media B.V. DOI 10.1007/s12132-017-9316-1

Sinthumule, N.I., \& Mkumbuzi, S.H. (2019). Participation in Community-Based Solid Waste Management in Nkulumane Suburb, Bulawayo, Zimbabwe. Resources. 8, 30; doi: 10.3390/resources 8010030. Available at www.mpdi.com/journal/resources.

UNEP. (2013, October). Taking the Pulse of the Planet; connecting science with policy. Global Environmental Alert Services (GEAS).

United Nations General Assembly. (2015). Sustainable Development Goals. (SDGs), transforming our world by 2030. 